Chapter 3

\title{
Psoriasis as a Chess Board - An Update of Psoriasis Pathophysiology
}

\author{
Robyn S Fallen, Anupam Mitra, Laura Morrisey and \\ Hermenio Lima
}

Additional information is available at the end of the chapter

http://dx.doi.org/10.5772/53580

\section{Introduction}

By virtue of the dynamic nature of the scientific process, the description of the pathogenesis of a disease is always a work in progress. Each day new research shapes and refines our understanding of disease processes; an attempt to describe the current scientific understanding provides merely a snapshot of a body of knowledge that is constantly changing. However, characterizing a disease using homeostatic and physiological terms allows the creation of a framework to convey the most up-to-date theories while maintaining the potential for their evolution.

The complex nature of psoriasis can similarly be unveiled through understanding the historical context of our current understanding, examining prevailing hypotheses, and extrapolating horizons for new research. To develop a framework for understanding the pathogenesis of psoriasis and its evolution, the first perception to be changed is the prevalent view of the immune system. The general notion of the immune system as a defense arrangement that protects us against the microorganisms must be changed. This view results from a reduction of the process itself and, as mentioned by Dr. Nelson Vaz, are features derived from the birth of the immunology [1]. Immunology, as a scientific field, is new in the history of medicine. Immunology developed in a century marked by the First and Second World War and Cold War tension. Hence, many models to exemplify the immunological concepts were simplified and described in relation to war affairs to facilitate the understanding of this science. In this model, if a microorganism attacks a human being, the individual advocates the use of the immune system to counteract. Another simple aspect is the teleology that prevails in the immune science. For example, the T lymphocyte exists to kill cells infected with intracellular parasites. This model full of logic and consequences does not apply in many other areas of 
medical and non-medical sciences. As such, it is necessary to move to a new approach to describing the relationship between the immune system and environment. In this new paradigm, the immune system does not react, but rather interacts with the environment, and this contact is made through the skin and mucous membranes. This interaction, causal or not, can have different results. In most cases, there is a balance, imperceptible to other sensory systems, which is characterized by the integrity of what we call health. Thus, homeostasis disorders or imbalances lead to disease. This seems obvious when written, but this search for stability has continuity for the duration of the life of a given organism. If we consider the immune system a sensorial system, it interacts with the modifications of the environment, detects this information of change, and responds with adjustments to maintain homeostasis. You might reduce this view by comparing it to an engine that runs under different types of fuel mixture. It detects the different fuel composition and changes the compression ratio of the cylinder for better efficiency to keep the car moving.

For better observation of this psoriasis pathogenesis, we will make a technical simulation of the immune system in a specific situation. This simulation will cover various aspects of immune response, spanning from the beginning of the inflammatory response, to specific immune response through the development of psoriasis. Here, under a historical perspective and comparing with a chess game, the main objective is to provide insights on the central role of some of these cytokines and immunological pathways in psoriasis pathophysiology. Through this, the aim is to explain some facts of modern immunodermatology that might be useful for clinicians to understand the basis of the immunology of psoriasis. Moreover, an important goal is to dispel some misinformation that might have a negative impact on the use of new immunomodulators and medications available for use by physicians. Treatment basis and therapeutic response experience strongly supports the use of immunomodulators as important modalities in the treatment of psoriatic arthritis and plaque psoriasis. Studies with these therapeutic agents, which act in different steps of the psoriatic inflammatory cascade, have also shown significant efficacy. [2].

Directly targeting this inflammatory cascade, blocking specific cytokines is a modern treatment option for psoriasis and other autoimmune diseases [3]. The rationale for this therapy arises from pathophysiology; in different autoimmune diseases there is an increase in production of proinflammatory cytokines by the immune system. Inflammatory cytokines, like many other cytokines, have an important role in both maintaining health and participating in disease manifestation [4]. This chapter discusses the pivotal role of some of these cytokines in psoriasis pathophysiology, how our understanding of its mechanism evolved, and how blocking the effect of a specific cytokine might substantially improve the disease condition.

\section{Pre-biologic immunological history of psoriasis}

Psoriasis is a common skin disease with extra-cutaneous manifestations. It is characterized by chronic inflammation of the skin with changes in the maturation of keratinocytes, which is manifested by the hyperproliferation of the epidermis. Moreover, inflammatory reaction can 
be found in other systems of the same patient. However, this disease is mediated by $\mathrm{T}$ lymphocytes, orchestrated by orchestration multigenic and environmental factors. The altered immune system is essential for the inflammation present in both the skin and other organs. A concept of a multi-systemic disorder involving different organs of the patient and reflects a better understanding of the complex pathophysiology of this disease [2].

The concept of biological therapy for psoriasis has been derived from its etiopathogenesis. As in a chess game, these new forms of treatment have evolved from an integration of the knowledge of interactions between the immune system cells (pieces) and its cytokines (movements) that initiates the pathologic processes and ultimately leads to the development of the clinical features of psoriasis.

In ancient records, the initial causes of psoriasis were attributed to multiple sources ranging from the divine power to racial associations [5]. An unknown infectious organism was indicated as a source of psoriasis in 1927 [6]. Later, its etiology was described as primarily and essentially an epidermal problem, independent of immunologic phenomena [7]. The main objective of cytotoxic drugs developed in the $20^{\text {th }}$ century, such as methotrexate, was to reduce keratinocyte proliferation. Immunological studies on psoriatic patients identified changes in humoral immune reactions as part of the overall problem but not the cause [8, 9]. Efficacy of the cytotoxic drugs in the late 1960s paved the road for ideas about the role of the immune system in psoriasis [10,11]. Further investigations in the 1970s revealed the role of immunologic factors in psoriasis. However, the dominant thought was that psoriasis was a disease of faulty epidermopoiesis due to impaired autocontrol mechanisms [12]. Hunter et al. wrote "More work on cell turnover and its regulation will give the clue to psoriasis" [13].

Other studies in the 1970s revealed the role of immunologic factors in psoriasis. Histopathologic examination of psoriatic lesions showed a striking resemblance to cellular inflammatory reactions observed in allergic contact dermatitis [14]. A selective immunosuppressant effect was the initial hypothesis used to describe the pathological cellular immune response [15]. Soon thereafter, the discovery of a soluble factor that played an important role in keratinocyte proliferation helped to form the cytokine-based theory for the induction/maintenance of the inflammatory and proliferative cascades of psoriatic lesions [16]. Subsequently, an integrated theory explaining the etiopathogenesis of psoriasis came into play: in a genetically susceptible patient, immunological factors trigger rapid turnover in the epidermis resulting in the development of psoriasis [17].

The fundamental confirmation that any defect of the skin is not sufficient by itself to maintain a psoriatic lesion occurred in the subsequent decade. Some studies confirmed that $\mathrm{T}$ cells and soluble factors could stimulate keratinocyte proliferation. Immunophenotyping of psoriatic lesions showed mixed T lymphocyte (TL) cell populations (CD4 and CD8) and Langerhans cells (LCs) distinct from normal skin [18]. This cellular infiltrate changed with topical or systemic treatment $[19,20]$. In another study, failure of plasma exchange and leukapheresis ruled out the major participation of humoral immune system in the pathogenesis of psoriasis [21]. Thus, the cellular arm of the immune system was implicated in psoriasis for the first time during the 1980s [22]. 
During the 1990s, research on immunopathogenesis of psoriasis thus focused on the cellular and the cytokine components of the immune system. Researchers observed that an influx of activated T lymphocytes, mainly CD4+, HLA-DR+, Interleukin (IL)-2 receptor - CD25+ T cells, was one of the earliest events of psoriasis [23]. Based on Mosmman and Coffman's publication [24], these T lymphocytes were classified as Thelper (Th) type 1 cytokine producers (Th1) [25]. They produce Interferon (IFN)- $\gamma$, IL-2, and Tumor Necrosis Factor (TNF)- $\alpha$ cytokines and implied that a cellular type 1 reaction was responsible for psoriasis (Figure 1). The observation of the historical evolution of the extra-cutaneous manifestations of psoriasis and their pathogenesis confirms the idea of a multi-organ disease with complex immunological pathways [2].

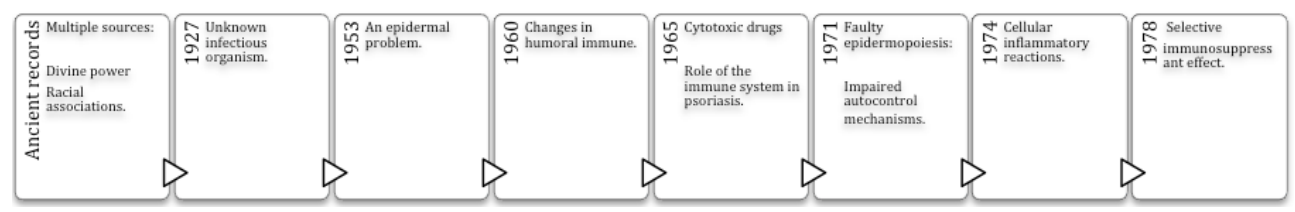

Figure 1. Time line of development of psoriasis pathophysiology: From unknown to epidermal problem through Immunological disease.

\section{Psoriasis: Many pieces and movements on a complex chessboard}

Psoriasis plaque is induced and maintained by multiple interactions between cells of the skin and immune system. It seems that the pathogenesis of psoriasis could involve a stage of cellular infiltration resulting in epidermal (keratinocyte) proliferation. Each inflammatory pathway (IL-12/Th1, IL-23/Th17, and IL-22/Th22) has its impact on psoriasis development [26]. The different pathways are based on the fact that $\mathrm{T}$ helper cells can be skewed towards mutually exclusive subtypes on the basis of the cytokine environment $[27,28]$. The process of $\mathrm{T}$ lymphocyte reactivation results from interaction of $\mathrm{T}$ cells with the resident antigen presenting cells (APCs) found in plaque psoriasis, which in turn determines the cytokine environment and Th1/Th17/Th22 pathway.

The primary etiopathogenesis of an autoimmune disease, or the activation of Th1/Th17/Th22 pathways, is the dysregulation of immune system activation since the development of autoreactive lymphocytes occurs in the same basic manner as lymphocyte activation. The understanding of this process or processes is very important to maintain the balance of the normal performance of the immune system. Briefly, it is comparable to the process to find the moment where one player lost the chess game based on the retroactive analysis of his moves. Cytokines are the possible moves of different pieces of the game. Many pieces can produce the same movement but with different results. The moves are the key players in generating or establishing a specific immune system reaction. Therefore, blocking cytokines that maintain autoimmune activity has become one the most successful strategies for autoimmunity therapy. A new balance can be established with the removal of a key piece or blocking of a lethal move so that the critical players are removed from the chessboard of an autoimmune response. 
As with any other disease involving the immune system, psoriatic manifestation begins with Antigen-Presenting Cells (APC) activation by an unknown trigger. Different factors including infections, trauma, medications, and emotional stress can initiate the initial phase of the disease. Such factors can activate keratinocytes to release cytokines such as IL- 1 and TNF- $\alpha$, initiating the effector phase of psoriasis by activating resident skin macrophages and Dendritic Cells (DCs). DCs migrate to the regional lymph node, which initiates T lymphocyte activation in response to the stimuli. This is part of the working model of the immune synapse of $\mathrm{T}$ cells in psoriasis, integrating T cell signaling pathways in autoimmunity [29]. This association leads to the production of IL-12/Th1/IFN- $\gamma$ pathway. Many molecules in the plasma membrane of both cells, other than the Major Histocompatibility Complex (MHC) and T Cell Receptor (TCR), are involved in this phase and can be used as a target molecule for the treatment of psoriasis. The most important molecules are ICAM-1, LFA-3, and CD80/CD86 in the DC and LFA-1, CD2, and CD28 in the T cell, respectively. Alefacept, a fusion protein used for psoriasis treatment, blocks $\mathrm{T}$ cells activation by interfering with $\mathrm{CD} 2$ on the T cell membrane, thereby blocking the costimulatory molecule LFA-3/CD2 interaction [30]. Furthermore, it has recently been discovered that IL-27 suppressed macrophage responses to TNF- $\alpha$ and IL-1 $\beta$, thus identifying an anti-inflammatory function of IL-27 [31].

Continuing the evolving complex immunological chess game, the activated T lymphocyte Th1 cytokine producers leave the lymph node and migrate to the skin where cytokines like TNF$\alpha$, produced by keratinocytes and activated DCs, facilitate T lymphocyte diapedesis into the dermis and epidermis [32]. The TNF- $\alpha$ induces the skin immune cell infiltration by inducing chemokines and upregulating adhesion molecules on the endothelial cells of dermal vessels. Adhesion molecules such as CLA and LFA-1 on the T lymphocyte membrane and E-selectin and ICAM-1 on the endothelial cell membrane are involved in this process. Efalizumab, a Humanized Anti-CD11a, Anti-LFA-1 molecule has been used in psoriasis treatment by blocking the TL migration to the skin [33]. In summary, dendritic cells and effector T-cells are important in the development of the psoriatic lesion, and cytokines produced by these cells stimulate keratinocytes to proliferate and increase the migration of inflammatory cells into the skin, promoting epidermal hyperplasia and inflammation [34].

\subsection{Chessboard: The skin's influence on psoriasis development}

The primary cause of psoriasis has not been not found. Factors such as genetics and environmental exposure are now recognized to play a role in psoriasis development. Certainly, autoimmunity does not appear to be the only, or necessary, component to the development of psoriasis. However, psoriasis is a manifestation of skin immune reactions. Inflammation is a key feature of pathogenesis, with all inflammatory cell types implicated in psoriasis pathology by multiple interactions between cells of the skin or from other organs and the immune system. Nonetheless, the etiology of psoriasis as an epidermal problem or a disease of faulty epidermopoiesis due to impaired autocontrol mechanisms is not completely wrong. Keratinocytederived inflammatory molecules ampliy skin immune responses associated with psoriasis, and contribute to the disease process and clinical phenotype [35]. Psoriatic keratinocytes respond aberrantly to cytokines and show altered intracellular signaling pathways [36]. 
Heterogeneous functions of other skin resident cells, such as fibroblasts and endothelial cells, may also contribute to the pathogenesis of psoriasis [37]. Furthermore, leukocytes that infiltrate skin lesions have been shown to be involved in the pathogenesis of this disease [38]. Despite parallels to the chicken and egg causality dilemma, all of these contribute to the presentation in patients suffering from psoriasis that is later observed by clinicians.

\subsection{Immunopathogenesis of psoriasis is a teleological model}

From the previous data, it is well known that the immunopathogenesis of psoriasis is complex. It involves alterations in the innate and acquired immunologic system. In the most accepted models, cells of the skin when activated produce immunological mediators that act upon the cells of the specific immune system. The action is amplified by the opposite direction [39].

The most studied theories about autoimmune disease etiology associate the immune dysregulation and loss of tolerance due to the impact of environmental factors on genetically susceptible individuals. The literature has always highlighted the importance of the microorganism in the lack of immune homeostasis in psoriasis. The linkage of antigens of infectious agents to the toll like receptors can activate keratinocytes and other cells to release innumerous chemokines, cytokines and growth factors. Activated keratinocytes are capable of recruiting and activating $\mathrm{T}$ cells. Therefore, infections are considered an important component that can unleash the manifestation of psoriasis[40].

\subsection{Dissociation between immunopathogenesis and immunological concepts}

In accordance to the actual immunopathogenesis models for psoriasis, the skin is the body's primary defense against external invasion. However, the keratinocytes, in defending the body against the microorganism, induces the migration of cutaneous lymphocyte-associated antigen (CLA) positive T cells. Finally, T cells play a central role in initiating and perpetuating the immunological mechanisms of psoriasis [41].

In this context, the possibility arises that endogenous, normal, housekeeping self-proteins might be epitopic targets in autoimmune responses in psoriasis. The transition from selfreactivity to the autoimmune pathology appears to be mediated by a complex network of overlapping phenomena [42]. However, all studies about the antigen identification in psoriasis, like in many other autoimmune diseases, did not find an optimal autoantigen for studying the relationship between similarity level and immune responses [43].

Therefore, the actual models of immunopathogenesis of psoriasis break the specificity basic statement of immunology. There are historical reasons for the dissociation between immunopathogenesis models and immunology concepts. Immunology emerged as a biomedical science, concerned with host defense and production of anti-infectious vaccines. Ehrlich's sidechain theory explained the anti-infectious protection granted by vaccines and serotherapy [44]. It was the first steps of the development of initial cognitive metaphors, such as recognition and memory.

The clonal selective theory of antibody formation in the 1950s was a new evolution and the initiation of neo-Darwinism in Immunology. The selective theories of antibody formation 
resulted from the union of Immunology with Darwin's theory of evolution. They also amplified the "Defensive metaphors". Lymphocytes are supposed to respond specifically to stimuli. Except for brief moments of activating or inhibiting interactions, lymphocytes are believed to act independently from each other. Therefore, the immune system defends the body by amplification of specific lymphocytes.

\subsection{Defensive metaphor}

In seeking to understand the unknown, mysterious, or abstract, the human mind draws comparisons to the known, familiar, and concrete. When these comparisons are made explicit, we call them metaphors or analogies. Scientists draw on metaphors when struggling with phenomena that defy easy observation, such as the immune system. Immunology developed many metaphors based on the scenario of its development. The naissance of immunology was marked by the great World Wars and the Cold War tension. Consequently, immunological concepts were simplified and described as war affairs.

The war metaphor for the immune response is appealing, in part, because it seems to create a deeper understanding of the rules that direct the immune system actions. The consequence of immunologists' fondness for war metaphors, the authentication of the models has hardly been tapped. However, any metaphors used to explain the immune system evoke intuitive notions of strategy, skill and competition. Rarely do they indicate a deep understanding of the particular clinical variation present in the arenas of medical life.

The underlying principle in this framework is the immune system as a "defense system." When it is said that the immune system defends the body, there is the use, intentionally or not, of a metaphor. This is also a teleological argument (from the Greek $\tau \dot{\lambda} \lambda$ o for "end", "purpose", or "goal"). Teleological argument is a knowledge or explanation about a fact that relates to a final question. Teleological reasoning is an anthropomorphic interpretation used in science. Therefore, it is given that there is an end or a function for the biological being or immune system. However, there is not much teleological argument in physics or other natural science fields. Do you know any reason why the earth gravitates around the sun?

Immunologists are in a comparable position to use metaphors inasmuch as the cellular and molecular relationships that form the immune response are things that cannot readily be seen. Famous and basilar modern immunological metaphors include viewing the immune system as a planning body at a multidimensional space in which the lymphocytes are developing defensive strategies against invaders or irritants. Another side of this favorite metaphor is that of the main reason why bacteria invade the bodies is because those bodies harbor environments where the bacteria can survive and multiply. The immune system protects the body from invaders like bacteria, viruses and parasites.

There are consequences to this metaphor interpretation. The immune system does not act as one structure or system. A system is described as a collection of elements connected to each other in such a way that acting upon one element has repercussions upon all the others. Lymphocytes are supposed to respond independently specifically to antigen stimuli. There- 
fore, lymphocytes do not interact with the organism or with other lymphocytes. They are clonal units. Thus, lymphocytes cannot organize themselves in a system.

In the actual stage of the clonal selection theory acceptance and consequent metaphor interpretation, the proposition of significantly different concepts or description of the immune system have been excluded from the scientific media. The net result of such a theoretic narrowness is the characterization of a massive variety of cellular or molecular independent components involved in immunological activity. Therefore, the expansion, contraction and regulation of specific clones of lymphocytes are insufficient to generate all known immunological phenomena. Finally, the lack of a different view about the immune system followed in a flagrant inability to create new vaccines, to understand and treat allergies or autoimmune diseases as psoriasis.

\subsection{Game theory as a new proposal for immunopathogenesis of psoriasis}

Does the interpretation of the data in immunology, as it is today, represent the only possible way to have an immune response? Is there a new model where the immune system can be explained and the immunopathogenesis of autoimmune diseases as psoriasis can be interpreted? This is a logical question that should follow the previous assumptions.

Consistent with the position that the details of a immune response matter, any other proposition begins by reviewing and incorporating the accepted rules, constraints, and properties available for the immune system - the Immunology game's inner logic. The application of game theory to Immunology thinking is our new proposition to explain autoimmune diseases and other immunologic responses. The objective here is to begin taking games seriously as potential sources of insight into the relationship that determines the Immune system.

Game theory is a set of concepts aimed at decision making in situations of competition and conflict, as well as of cooperation and interdependence, under specified rules [45]. Game theory metaphors began with the idea regarding the existence of mixed-strategy towards equilibrium. The discordant note of this view of game theory with the actual immunological response is the prevailing opinion among game theorists that any interaction will eventually converge to Nash equilibrium predictions under the right conditions. Although the initial application of game theory to immunology does not involve any of the requirements of the Nash equilibrium, the human homeostasis conforms nicely to predictions of the Nash equilibrium or relevant refinement. Absence of homeostasis or disease is the lack of stability in the immune system concept.

Researchers are starting to realize that this simplistic view of the immune system as defensive system needs a radical rethink [46]. The focus has been less on equilibria that correspond to a notion of rationality or teleologism, but rather on ones that would be maintained by evolutionary forces. In this new view, the skin has no longer been thought of as a mere physical barrier to attack by pathogens. Recent studies suggest the interplay between the skin's resident microorganisms, known collectively as the skin microbiome, and immune mediated organspecific diseases [47]. Increasingly, it has been recognized that disruptions in the commensal microflora may lead to immune dysfunction and autoimmunity. Therefore, the microbiome 
influence the host's immune system [48]. In particular, there are new findings on the role of the microbiome in psoriasis [49].

Biologists have used game theory. The known game theory equilibrium in biology is the evolutionarily stable strategy (ESS) [50]. Additionally, biologists have used evolutionary game theory and the ESS to explain many seemingly incongruous phenomena in nature. Paradoxically, it has turned out that game theory is more applied to biology than to the field of immunology for which it can be an evolutionary metaphor. Considering some of the ways in which game metaphors have been used in biology analysis, observing that most game metaphors involve only vague and fleeting references to some generic game with the goal of making a preconceived point. We contrast this with analogies in the natural sciences, in which knowledge of a well-understood phenomenon is used to shed light on another that is less well understood. A new idea has to propose a nonteleological view including all possible natural evolutions, which will necessarily generate other set of problems and enigmas. A nonteleological thinking is a way of viewing things as they are, rather than seeking explanations for them [51]. However, the practicality of a nonteleological view in immunology is null nowadays [45].

In summary, although the costs of infections to immune system are meaningful, a growing body of evidence supports a general benefit associated with infectivity. Reducing the risk of uncontrolled inflammation and limiting the tissue damage caused by injury are important features of host defense against pathogens, but would be beneficial in a variety of autoimmune diseases [52]. Game theory may help to appreciate the benefits of immunity to infection. This is the challenge for the new homeostatic immune system metaphors that explain the autoimmunity mechanisms as in psoriasis.

\section{The initial biologic treatments for psoriasis and implications for the understanding of immunological mechanism of psoriasis}

Psoriasis was defined as Th1 type of disease based on the early understanding of the Thelper subsets. The initial belief was that infiltrating $T$ cell subpopulations derived from the draining lymph node regulated the development of the inflammatory responses in the skin by producing IFN- $\gamma$ and TNF- $\alpha$ [53]. The Th1-derived cytokines produced by these infiltrating Th1 favors further Th1 cell access, upregulates keratinocyte chemokine production, and supports dermal DC myeloid type (DC11c+) activation. In response to this cytokine activation, keratinocytes and other cells produce a plethora of immune mediators, which induce and amplify inflammatory responses in the skin [54].

As a result, two logical biologic therapeutic approaches were tested: one was the administration of counter regulatory type 2 cytokines and the second was the blocking of type 1 cytokines. The use of monoclonal antibodies or fusion proteins to neutralize cytokines started to be used on a large scale because of their efficacy and practicality.

These studies have proved to be a useful biological model and test ground for evaluation of the skin immune system and psoriasis. Although these drugs were not initially developed in 
the treatment of psoriasis, but rather in rheumatoid arthritis and Crohn's disease, the observation that Crohn's disease patients with psoriasis were improving while on anti-TNF therapy profoundly influenced the studies that were to come [55].

Although clinical response to anti-TNF suggested a role for Th1 cells in psoriasis, evidence coming from other studies demonstrated that Th1/Th2 paradigm and key role of TNF were not sufficient to explain the full pathogenesis of psoriasis. At this point some academic resistance to an immunological pathogenesis for psoriasis was raised [56]. However, the main interpretation was that an important piece of the immunological cytokine puzzle was missing. Many other pieces would be involved in such a complex game.

\section{The IL-12/23 and its role in the immunopathogenesis psoriasis}

The initial quest for the missing cytokines was the search for pathway inducers. Researchers first noted that IL-12 is crucial for Th1-cell differentiation [57]. IL-12 signaling via its receptor activates Stat4 (signal transducer and activator of transcription 4), which upregulates IFN- $\gamma$. IFN- $\gamma$ activates Stat1, which enhance T-bet (T-box expressed in T cells), the leading TH1 transcription factor, further enhancing IFN- $\gamma$ production and downregulating IL-4 and IL-5 expression [58]. IFN- $\gamma$ mediates many of the pro-inflammatory activities of IL-12. Phagocytes and Dendritic Cells (DCs) are the main producers of IL-12 in response to microbial stimulation [59], and this relationship links innate resistance and adaptive immunity. The main function of IL-12 is resistance to infections with bacteria and intracellular parasites. However, it plays an important role in the Th1 response that sustains organ-specific autoimmunity [60]. The use of anti-IL-12 mAb (monoclonal antibody) in an experimental model of psoriasis also suggested the therapeutic value of blocking IL-12 in humans [61], although side effects of the drug limited further development in this area.

For many years, the IL-12-dependent Th1 cells were thought to be essential for the induction of autoimmunity. However, during the Th1/Th2 paradigm studies, an IFN- $\gamma$-independent mechanism responsible for the pathogenesis of many inflammatory diseases and psoriasis was found [62]. IL-12 and IL-23, as discovered previously from human DNA sequence information, share the subunit p40 [63]. The use of anti-IL-12/23p40 and anti-IFN mAb ultimately established at least part of the solution to the riddle. Only neutralization of p40, but not of IFN- $\gamma$, ameliorated chronic inflammatory reactions. This finding suggested that the latter cytokine, IL-23, accounted for the IFN- $\gamma$-independent mechanism of inflammation.

Identified from human DNA sequence information, IL-23, like IL-12, is also a heterodimeric cytokine composed of the same subunit p40 paired with the unique p19 [64]. It has been reported that IL-12 and IL-23 are up-regulated in psoriatic skin [65]. Human studies with antiIL-12p40 have shown that this treatment not only ameliorates psoriasis, but also downregulates type 1 cytokines and IL-12/IL-23 in lesional skin [66]. Besides sharing the subunit p40 and signaling through similar receptors, IL-23 and IL-12 are responsible for driving different T-cell subsets. Moreover, presence of abundant IL-23+ dendritic cells as well as elevated mRNA expression for both subunits of IL-23 (IL-23p19 and IL-23p40) in psoriatic lesions supports the 
role of IL-23 in the pathogenesis of psoriasis [65, 67-69]. Genetic studies have revealed that polymorphisms in IL-23p19, IL-12/23p40, and IL-23R are associated with increased risk of psoriasis [70-72]. Furthermore, in an animal xenograft model of psoriasis, Tonel G et al showed that treatment with anti human IL-23 mAb causes statistically significant reduction of acanthosis and papillomatosis index in grafts of mice in comparison to isotype controlled mice. Moreover, they found comparable efficacy of anti human IL-23 mAb with anti TNF- $\alpha$ (infliximab) in blocking the development of psoriasis. They also showed a significant decrease in CD3+ T cells mainly in the epidermis of mice treated with anti human IL-23 mAb in comparison to control mice [73].

IL-23 could also mediate and sustain late-stage chronic inflammation by the production of IL-17 by Th17 [74]. IL-23 plays an important role as a central growth factor [75-77]. In presence of TGF- $\beta$ and IL-6, IL-23 helps in development of Th17 cells whereas TGF- $\beta$ is inhibitory to production of IL-22 [78-80] (Figure 2).

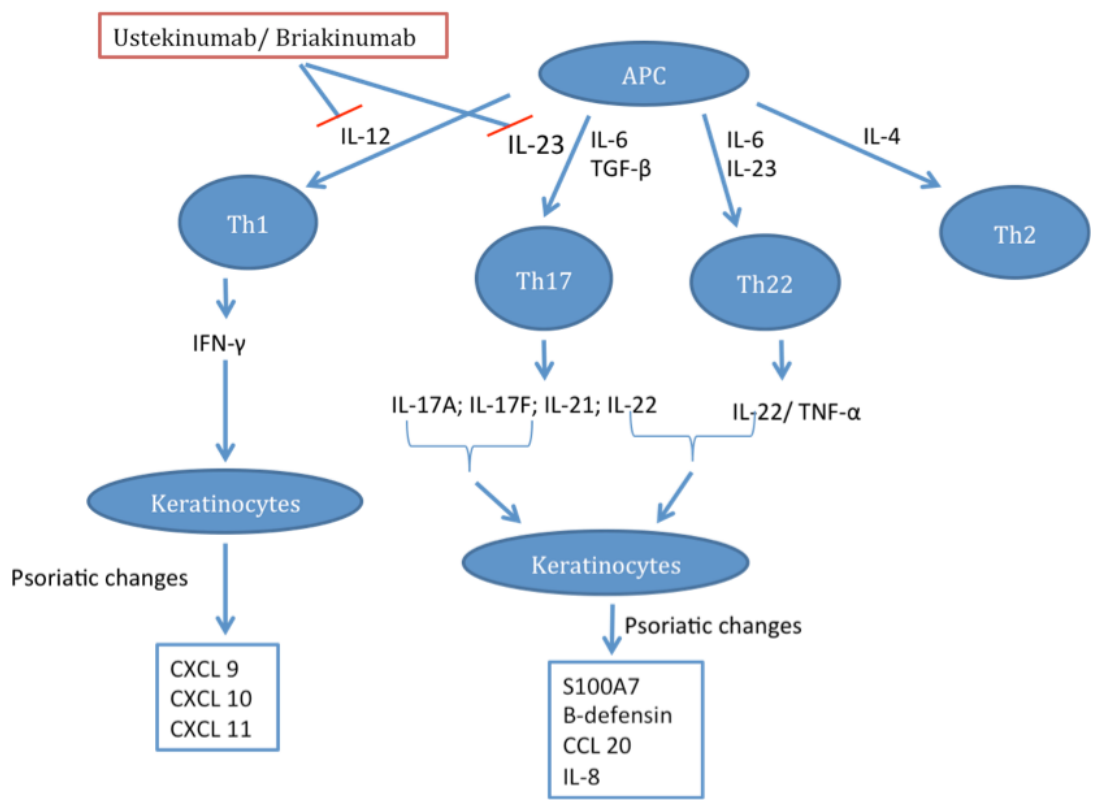

Figure 2. The pivotal role of some of IL-12 and IL-23 in psoriasis etiopathogenesis: How blocking the effects of these cytokines substantially improve the disease condition.

The IL-23/Th17/IL-17 immune axis was initially elucidated when IL-17 gene expression was induced by B. burgdorferi independent of IL-12 [81]. The IL-17-producing CD4+ T cells distinct from those producing either IL-4 or IFN- $\gamma$ were called Th17 [82]. Patients with psoriasis have increased Th17 cells as well as increased expression of mRNA for Th17 cytokines (IL-17A; IL-17F; TNF- $\alpha$; IL-21 and IL-22) and chemokines (CCL20) [83-87]. In psoriasis, Th17 cytokine IL-17A mainly induces cytokine and chemokine production by keratinocytes [84, 88, 89], 
whereas IL-22 induces proliferation of keratinocytes and production of antimicrobial peptides by keratinocytes [78, 90-92]. The role of IL-23 and IL-17 in psoriasis was further substantiated in some animal studies with recombinant IL-23 and anti IL-17A. In wild type (WT) mice, injection of recombinant murine (rm) IL-23 induces epidermal hyperplasia [93, 94], whereas, in IL-17 -/- mice showed less epidermal hyperplasia after repeated injection of rmIL-23. A recent publication by Rizzo et al showed that WT mice do not show epidermal hyperplasia to injection of rmIL-23 if they were treated with anti IL-17A antibodies [95]. A redundant cytokine model has emerged as the evolving explanation for psoriasis pathogenesis. It is based on the IL-12/Th1/ IFN- $\gamma$ - TNF- $\alpha$ and the IL-23/Th17/IL-17 immune pathways (Figure 3). The effectiveness of the anti-TNF treatment of psoriasis validated the first axis. The efficacy of antip40 (anti-IL12/23) treatment confirms the other [96].

\begin{tabular}{|c|c|c|c|c|c|c|c|c|}
\hline 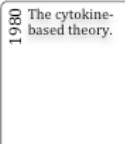 & 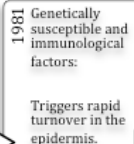 & $\begin{array}{l}\mathscr{Q} \text { CD4 and CD8 } \\
\text { CD and } \\
\text {. Ruled out the } \\
\text { g major } \\
\text { participation of } \\
\text { humaral } \\
\text { immune system. }\end{array}$ & 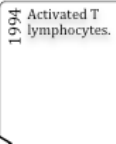 & $\begin{array}{l}\text { S Thelper (Th) } \\
\text { Stype 1. }\end{array}$ & 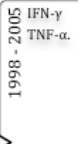 & 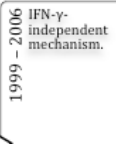 & 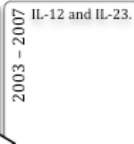 & $\begin{array}{l}\text { Redundant } \\
\text { ¿े cytokine model: } \\
\text { IL-12/Th1/ } \\
\text { IFN- } \gamma \text {-TNF-a } \\
\text { and } \\
\text { IL-23/Th17/ } \\
\text { IL-17 }\end{array}$ \\
\hline
\end{tabular}

Figure 3. Time line of development of psoriasis pathophysiology: From complex immunological disease through genetic participation until recent advances.

\section{Selective IL-23/Th17/IL-17 immune axis inhibition}

IL-23 favors the proliferation of the Th17 subtype and consequent production of IL-22 and IL-6 that stimulates the proliferation of keratinocytes. IL-17 favors infiltration of neutrophils into the skin forming the typical Munro's micro-abscesses with some participation of IL-22 [97].

Studies have demonstrated that anti-p40 (anti-IL-12/23) treatment is highly efficacious for psoriasis. Ustekinumab anti IL-12/23 antibody showed its efficacy and safety in three phase III trials recruiting 2899 patients. From two placebo controlled trials, PHOENIX 1 and PHOENIX 2, ustekinumab showed its efficacy in ameliorating psoriatic plaques, pruritus, and nail psoriasis [98]. (Table 1).

Remarkably, in a phase II multicenter, randomized, double-blind, placebo-controlled trial briakinumab, another human monoclonal anti-IL-12/23 antibody, 90-93\% of subjects in 4 dosing groups were able to achieve a PASI 75 [99]. This finding alone confirms the centrality of this pathway because these levels of efficacy have not been previously seen in studies with other agents [100]. Safety data for both agents is limited, but to date has been favorable.

One issue with anti-p40 therapy is that it inhibits both the classical IL-12/Th1/IFN- $\gamma$ and IL-23/ Th17/IL-17 immune pathways. IL-12 and IL-23 are related cytokines with differences in their biological activities. After binding to their receptors, different intracellular transcription complexes are activated [101]. IL-12 predominantly acts on naïve T cells and initiates the TH1 


\begin{tabular}{|l|l|l|l|}
\hline PASI scores & $\begin{array}{l}\text { Placebo } \\
\text { [n= 410] }\end{array}$ & $\begin{array}{l}\text { Ustekinumab (45 mg) } \\
{[\mathrm{n}=409]}\end{array}$ & $\begin{array}{l}\text { Ustekinumab (90 mg) } \\
\text { [n = 411] }\end{array}$ \\
\hline PASI 50 & $41(10 \%)$ & $342(83.6 \%)^{*}$ & $367(89.3 \%)^{*}$ \\
\hline PASI 75 & $15(3.7 \%)$ & $273(66.7 \%)^{*}$ & $311(75.7 \%)^{*}$ \\
\hline PASI 90 & $3(0.7 \%)$ & $173(42.3 \%)^{*}$ & $209(50.9 \%)^{*}$ \\
\hline $\begin{array}{l}\text { Physician's global } \\
\text { assessment (Cleared) }\end{array}$ & $0(0.0 \%)$ & $93(22.7 \%)^{*}$ & $115(28.0 \%)^{*}$ \\
\hline $\begin{array}{l}\text { Physician's global } \\
\text { assessment (Cleared or } \\
\text { minimal) }\end{array}$ & $20(4.9 \%)$ & $278(68 \%)^{*}$ & $302(73.5 \%)^{*}$ \\
\hline $\begin{array}{l}\text { Physician's global } \\
\text { assessment (marked or } \\
\text { severe) }\end{array}$ & $148(36.1 \%)$ & $15(3.7 \%)^{*}$ & $10(2.4 \%)^{*}$ \\
\hline
\end{tabular}

* $P<0.001$ Adapted from: Papp KA, Langley RG, Lebwohl M, et al. Efficacy and safety of ustekinumab, a human interleukin-12/23 monoclonal antibody, in patients with psoriasis: 52-week results from a randomized, double-blind, placebo-controlled trial (PHOENIX 2). Lancet. 2008; 371(9625):1675-1684.

Table 1. Clinical improvement at week 12 (PHOENIX II)

response. In contrast, IL-23 primarily affects memory T cells and expands the initiated Th1 inflammatory response by Th17 activity and maintains an adequate memory pool by compromising memory T cells [64, 101, 102]. Experimental studies suggest that IL-23/Th17/IL-17 immune axis blocking is sufficient to treat autoimmune inflammation [63].

Another way to block both pathways is the immunoregulatory role of IFN- $\gamma$. It is well-known that the administration of anti-IFN- $\gamma$ induces exacerbation of Experimental Autoimmune Encephalomyelitis (EAE) [103]. One possible explanation is the inhibition of IL-12/Th1/IFN$\gamma$ axis may destroy the regulatory role of IFN- $\gamma$ during chronic inflammation. TNF- $\alpha$, like INF$\gamma$, has a regulatory role in the immune system [104]. This might explain the observation that anti-TNF therapies can induce psoriasis and other autoimmune diseases in some patients [105].

An increase in efficacy and reduction of adverse events are the main drivers for new therapies. Infections, one type of adverse event, usually increase in patients receiving anti-cytokine therapy [106]. Studies with anti-IL-23 therapy will require surveillance for the development of opportunistic infections. Reports from patients with IL-12 and/or IL-23 cytokine deficiency syndromes alert to these potential infections in individuals under anti-IL-23 therapy. Invasive salmonellosis and mycobacterial diseases were present more often in patients with IL-12/IL-23 deficiency indicating that immunity against these microorganisms appears to be dependent of IL-12 and/or IL-23 [107]. However, antibodies against IL-12 and IL-23 may not cause a complete inactivity of these cytokines in a clinical scenario. For example, an experimental study showed that IL-23 plays a role in host defense against $P$. carinii, but it is not an essential one [108]. Clinical studies with anti-IL-12/23 treatment thus far have not increased the risk of non 
opportunistic or opportunistic infections [109]. A recent study showed that blocking IL-23 with monoclonal antibodies during BCG infection does not appear to affect the bacterial burden in immunocompetent mice. In contrast, blocking TNF- $\alpha$ or both IL-23 and IL-12 with anti-p40 dramatically enhances mycobacterial growth. From this study, antibody blockade of IL-23 alone rather than IL-12 might be preferable in patients who have been, or may be, exposed to mycobacterial infection [110].

\section{A new piece and a new move}

As previously mentioned, the IL-23 favors the proliferation of the Th17 and consequent production of IL-22. IL-22 mRNA presence was initially described in IL-9 stimulated T-cell lines and in concanavalin A (Con-A)-activated murine spleen cells [111]. Further studies demonstrated that IL-22 expression can only be observed in activated immunological cells [112]. However, other reports have revealed that some T cells express IL-22 independently of IL-17 [113]. Finally, a new distinct human memory CD4+ T cell subset with skin-homing properties was identified and denominated Th22 [114].

A preferential production of IL-22 cytokine by T cells (Th22, Th17, and Th1) is present in psoriasis lesions [86]. Many animal models indicate the role of IL-22 in psoriasis. IL-22 over-expressed transgenic mice developed psoriasis-like skin lesions [115]. In IL-22 -/mice, injection of IL-23 fails to induce epidermal hyperplasia indicating the role of IL-22 as a downstream mediator of tissue effects caused by IL-23 [78]. In a recent publication, Rizzo HL et al showed that to have IL-23 mediated epidermal hyperplasia, both IL-17 and IL-22 is required; any one of these is not sufficient to execute the effect of IL-23. They also showed that pre-treatment with anti IL-22 or anti IL-17A Abs block the rmIL-23 mediated epidermal hyperplasia in wild type mice [95]. In reconstituted epidermis model, IL-22 produces acanthosis dose dependently, which resembles psoriasis and either one of these alone is not sufficient to execute the effect of IL-23. The effects of IL-20 subfamily cytokines on reconstituted human epidermis suggest potential roles in cutaneous innate defense and pathogenic adaptive immunity in psoriasis [92]. In a study by Wolk $\mathrm{K}$ et al, a correlation was demonstrated between the plasma IL-22 levels and the severity of the disease [90]. IL-22 regulates the expression of genes responsible for antimicrobial defense, cellular differentiation, and mobility in keratinocytes and may play a: a potential role in psoriasis [90]. Moreover, IL-22 levels correlated with IL-20 levels, which is in accordance with the IL-22-induced keratinocyte IL-20 production [116]. This suggests that IL-22 and its downstream mediator IL-20 play an important role in the final steps of psoriasis pathogenesis. Sabat $\mathrm{R}$ and his group in their studies showed that IL-22 regulates keratinocyte function in several ways: a. IL-22 helps form a biological barrier of the skin by producing antimicrobial proteins (AMPs) like $\beta$ defensins, and S100 proteins. This may be one of the reasons that psoriatic patients have less skin infections. b. IL-22 interferes with physiological desquamation process of skin by inhibiting the terminal differentiation of keratinocytes. c. IL-22 plays a role in recruiting neutrophilic granulocytes in skin by inducing the production of chemokines; 
d. IL-22 indirectly helps in extracellular tissue degradation by inducing production of matrix metalloproteinases 1 and 3. IL-22 induces the production of IL-20, another IL-10 family cytokine which has similar effects as IL-22, thus resulting in amplification of the effects of IL-22 [117]. In a transgenic mouse model, it has been showed that IL-22 causes acanthosis, hyperkeratosis, and hypogranulosis, which are hallmarks of psoriasis. IL-22 acts through STAT-3 to impact the differentiation of keratinocytes [115]. IL-22 induces pro-inflammatory chemokines and antimicrobial proteins (AMPs) $\beta$-defensins (BDs), and promotes epidermal acanthosis and parakeratosis of keratinocytes [90, 118, 119]. Some synergistic effect was noted with other pro-inflammatory cytokines like TNF- $\alpha$; IFN- $\gamma$; and IL-17 [117]. Alone, TNF- $\alpha$ does not have much effect on terminal differentiation of keratinocytes, but when keratinocytes were co-cultured with IL-22 and TNF- $\alpha$, the effects of IL-22 were amplified. This kind of synergism was also seen with CXCL8 and IL-20 expression in keratinocytes co-stimulated with IL-22 \& TNF- $\alpha$. One possible explanation of this may be that TNF- $\alpha$ increases the expression of IL-22 receptor complex and also affects the IL-22 signaling pathway [115]. Thus, IL-22 and IL-20, but not IFN$\gamma$ or IL-17, are the key mediators of resulting epidermal proliferation. IL-22 acts through heterodimeric receptor complex composed of IL-22R1 and IL-10R2 [120]. IL-10R2 chain is ubiquitously expressed in all cells and is important component of receptor complexes required for IL-22, IL-10, IL-26 and IL-28 and IL-29, whereas the IL-22R1 chain is present in epithelial cells and hepatocytes [121]. Between the two subunits, IL-22 binds first to IL-22R1, the high-affinity receptor, and then IL-10R2, a lower affinity receptor [122]. To produce its effect, IL-22 acts through different signaling pathways, mainly signal transducer and activator of transcription 3 (STAT-3) and mitogen activated protein kinase [123].

This final move induces the vicious cycle of proliferation and inflammation of the skin characterized by the hyper-proliferative phenotype of keratinocytes in psoriasis. An anti-IL-22/ IL-20 approach would have a complementary role to the neutralization of $\mathrm{p} 40$. However, there has not yet been a human study to demonstrate such a role or anti-IL-22 therapy in the treatment of psoriasis.

\section{The other side of the chessboard: The role of $\mathrm{T}$ reg}

Today, reading a book or scientific article on immunopathogensis, one will observe that suppressor $\mathrm{T}$ cells, renamed regulatory $\mathrm{T}$ cells (Tregs), have become a central concept in immunological vocabulary [124]. Hundreds of publications on Tregs have validated the existence of this single line of $\mathrm{T}$ cells. The CD4+CD25+highFoxp3+ Treg subpopulation is developed in the thymus and may be peripherally induced during the course of a normal immune response. The model in which Tregs directly or indirectly modify activation and differentiation of pathogenic $\mathrm{T}$ cells by means of an effect on antigen-presenting cells is supported by in vivo analyses [125]. 


\subsection{Regulatory T cells: Development of an immunological concept}

Biological systems are subject to complex regulatory controls and the immune system is no exception. It is known that the immune system has the potential to generate lymphocytes against auto-antigens. Experiments, however, suggest that individuals cannot easily be immunized against their own tissues. Therefore, a suppression mechanism is necessary to control potentially pathogenic immune cells. Owen suggested that this tolerance against one's own tissues is acquired during the development of the immune system, and Burnet proposed that the clonal selective destruction of lymphocytes for auto-antigens occurs primarily in the thymus.

The destruction of auto-reactive lymphocytes is the primary mechanism that leads to tolerance, but we know that this system is not perfect. Self-reactive B and T lymphocytes can be isolated from normal individuals [126]. Nishizuka and Sakakura proposed another mechanism for controlling auto-reactive cells. They observed that mice thymectomized between the second and fourth days of life developed an organ-specific autoimmune disease. This target-organ destruction can be prevented by restoring $\mathrm{T}$ cells from genetically identical individuals. The generation of regulator $\mathrm{T}$ cells was proposed in order to explain this mechanism of autotolerance attributed to the thymus [127].

Other studies observed that the prevention of autoimmune diseases was diminished by the reduction of CD4+ T cells, but not of CD8+ T cells, indicating that regulatory cells belonged to the CD4+ T cell class of lymphocytes. Sakaguchi subsequently characterized these regulatory cells as natural CD4+CD25+ Tregs that express Foxp3 [128].

\subsection{Suppressor $\mathrm{T}$ cells: Regulatory $\mathrm{T}$ cells are suppressor $\mathrm{T}$ cells}

Another control point of the immune response is established when the normal immune response is initiated. A different mechanism must be set off in order to control the magnitude of the response and its subsequent termination. This regulation should contribute to limiting clonal expansion and effector cell activity. Soon after the discovery that Tlymphocytes function as helper cells for B-lymphocytes, RK Gershon proposed that they could also act as cells capable of suppressing the immune response [129]. This subpopulation of suppressor T cells was considered a controller of both auto-reactive and effector cells. A suppressor cell was functionally defined as a lymphocyte that inhibits the immune response by influencing the activity of another type of cell involved in a cascade of suppression factors, a network of anti-idiotypic T cells, and counter-suppressive cells [130].

Many of the experiments carried out contain data that support the existence of suppressor T cells. However, the mechanism responsible for these suppressive phenomena was never clearly characterized, and consequently interest in the field of suppressor T cells has gradually dwindled. The discovery of Th1/Th2 cells led researchers to abandon the concept of suppressor $\mathrm{T}$ cells. Suppression was instead attributed to counter-regulatory cytokines. As pointed out by Green and Webb, the letter "S" started to resemble a foul word in cellular immunology, and its use was considered synonymous of scarce data with excessive interpretation or a mystic phenomenon [131]. 
Suppressor T cells reappeared as regulatory T cells (Tregs) in the late 1990s when several subpopulations of $\mathrm{T}$ cells were identified as having the capacity to inhibit the proliferation of other cells. Shevach et al. were the first to call attention to the fact that regulatory $\mathrm{T}$ cells and suppressor T cells are the same [132]. Therefore, the term 'regulatory' gradually replaced the term 'suppressor'. The main problem, however, is not that cells are termed regulatory, but that they are considered to be suppressors. It is more appropriate to consider regulatory $\mathrm{T}$ cells as immune response directors instead of its suppressors.

\section{Regulatory $\mathrm{T}$ cells and psoriasis}

The regulation mechanism of the immune system by CD25+high Tregs is not well understood. Studies have not yet arrived at a simple mode of action. Whatever the mechanism, the homeostatic balance of the immune system is obtained by healthy cellular and humoral responses. Some inflammatory agents, whether physical, chemical, or infectious, induce an intense immune response. This immune response against them frequently results in tissue damage that could be more intense if it were not for the interference of regulatory mechanisms [133]. As has already been specified, Treg cells help limit the damage caused by a vigorous immune response. Natural Treg cells may respond to an ample variety of auto-antigens, although there is evidence that they may also respond to antigens expressed by microbes. Induced regulatory T cells, such as TR1 or Th3, may develop from CD4+ T cells when exposed to specific conditions [134].

Similarly, excessive activity of Treg cells may limit the magnitude of the immune response, which may result in failure to control an infection. On the other hand, the absence of the T regulator may result in intense inflammation and autoimmune dermatitis. Tissue damage may also result from the development of effector cells against their own auto-antigens (Figure 4).

Psoriasis is sustained by the activation of pathogenic T cells. The regulatory expression of skin diseases discusses the action exerted by regulatory T cells, especially CD4+CD25+high Tregs on psoriasis. Various types of influence of these cells suggest that they may act by suppressing or augmenting immunity $[135,136]$. The control of Treg cells may affect the results favorably or may be deleterious. There is no definitive view. In psoriasis, studies have shown that the subpopulation of CD4+ T lymphocytes in peripheral blood, phenotypically CD25+high, CTLA-4(+), Foxp3high, is deficient in its suppressor functions. This is associated with an accelerated proliferation of the CD4+ T cell response [137]. The presence of non-functional CD4+CD25+high Treg cells in peripheral blood and in tissues may lead to a reduced capacity to contain pathogenic $\mathrm{T}$ cells and to a hyperproliferation of the psoriatic plaque in vivo. These findings represent a critical component of this autoimmune disease and may have implications for potential therapy by manipulation of CD4+CD25+high Tregs in vivo. However, other factors, such as the immune status and genotype, and the presence of concomitant diseases or other infections may also have an influence. The manipulation of this balance can be explored therapeutically. 


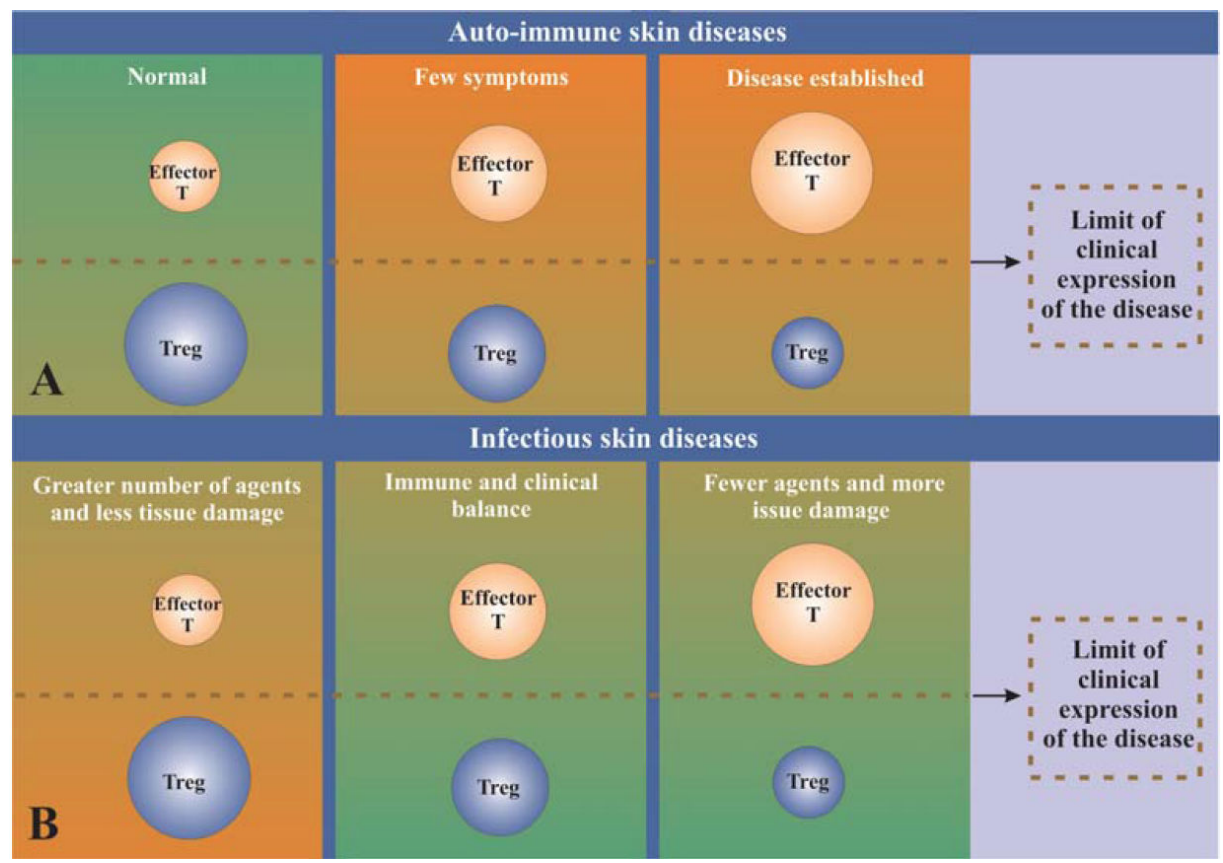

Figure 4. Immune response regulation mechanisms. The force balance between Tregs and the effector T CD4+ cells may present in a different manner depending on being an autoantigen or a pathogen. In A portion, the clinical expression of autoimmune skin diseases is shown. In this case, there is clinical manifestation only when the number and function of Tregs are significantly reduced. B portion displays clinical manifestations that may occur in extreme cases. In case of excessive Treg function, the result shows reduction of effector lymphocytes against the pathogen, an increase in its number and less tissue damage. The contrary applies to effector cells against the pathogen that surpass the number and function of Treg. The ideal immune and clinical response occurs when there is a balance between functions

\subsection{Clinical and therapeutic consequences of regulatory $\mathrm{T}$ cells}

An improved understanding of the role of $\mathrm{T}$ regulators in psoriasis may lead to the identification of new targets for treatment. More specifically, the goal is to manipulate natural regulator cells or those induced by means of an increase or decrease of their function, depending on the circumstances. 
Auto-injections of regulatory $\mathrm{T}$ cells are a promising approach to modulation of inflammation and autoimmune diseases [138]. Nevertheless, there is a significant decline in the function of natural CD4+CD25+high Treg cells of peripheral blood in patients with autoimmune diseases when compared to that of healthy individuals. In order to overcome this difficulty, cytokines were used to stimulate the growth of regulator T cells. IL-15 allows a significant in vitro expansion of regulator cells [139]. Natural CD4+CD25+high Treg cells obtained by ex vivo expansion through stimulation with allogeneic antigen-presenting cells and IL-2 were capable of modulating the graft-versus-host disease (GVHD). Induction of natural CD4+CD25+high Treg cells may facilitate the establishment and maintenance of immunological tolerance. Depletion of natural CD4+CD25+high Treg cells may be an effective way of reversing the tolerance induced by malignant tumors and increasing the activity of the immune system against cancer epitopes [140].

In the field of dermatology, the stimulation of Treg cells may be important in autoimmune diseases. For example, blockage of T lymphocyte stimulation, as in the use of the antibody associated with CTLA-4 (cytotoxic T lymphocyte-associated antigen 4-immunoglobulin, CTLA4Ig), reverts the development of psoriatic plaques [141]. In the clinical context, the effect of immunomodulator drugs on these cells warrants attention. For example, tacrolimus, an inhibitor of calcineurin, increases the inhibition of Treg cells in atopic dermatitis [142, 143]. Fludarabine reduces the frequency and suppressive function of natural CD4+CD25+high Treg cells [144]. Low doses of cyclophosphamide induce the inhibition of natural CD4+CD25+high Treg cells and consequently increase the immune response in an apparently paradoxical effect [145]. Along the same line, cyclophosphamide decreases the function, proportion, and number of natural CD4+CD25+high Treg cells that suppress the induction of contact hypersensitivity $[146,147]$. Currently, topical corticosteroids constitute one of the most effective treatments for psoriasis and other inflammatory skin diseases. These drugs are effective in inhibiting the function of Th2 cells, eosinophils, and epithelial cells. However, treatment with these drugs during the presentation of the epitope may result in an increased tolerance by suppressing the development of dendrite cells that secrete IL-10, which are necessary for the induction of T regulators. Therefore, treatment with corticosteroids may increase the subsequent effect of the $\mathrm{T}$ response and aggravate, on the long run, the course of inflammatory diseases [148]. This aspect may also be related to the rebound effect of inflammatory diseases once these drugs are removed.

\section{What is new?}

Studies suggest that IL-23/Th17/IL-17 immune axis blocking can be used to treat psoriasis [63]. Ustekinumab, anti IL-12/23 antibody, showed its efficacy in ameliorating psoriatic plaques, pruritus, and nail psoriasis [98]. This stimulated growing interest in the therapeutic potential of agents such as brodalumab, ixekizumab, and secukinumab that inhibit interleukin-17 signaling. These new group of biologics are in clinical trials. They use cytokine neutralization and receptor antagonism in treating psoriasis. Secukinumab and ixekizumab specifically 
neutralize interleukin-17A, whereas brodalumab is an antagonist of the interleukin-17RA receptor [149-151].

As previously mentioned, IL-23 favors the proliferation of the Th17 and consequent production of IL-22. Fezakinumab (ILV-094, Pfizer) is a fully human monoclonal IgG $\gamma$ antibody to IL-22 under study for the treatment of rheumatoid arthritis and psoriasis [152].

Nonetheless, there is no single new data about the basic mechanisms of psoriasis development despite the cytokine and anti-cytokine therapies widely used.

\section{Conclusion}

In medicine, a gold standard is the intervention believed to be the best available option. Given the proven role of many cytokines in psoriasis, substantial interest exists in targeting them with neutralization immunotherapy. If Th1/Th17/Th22 pathways operate in different steps of psoriasis development, then targeted blockade place biologics as the standard-setting paradigm for therapy and understanding of the pathogenesis of psoriasis. However, large studies are needed to provide information on the therapeutic effects, adverse events of any anticytokine therapy, and their place in the treatment of psoriasis and other skin diseases. To complement this approach, a detailed comprehension of the associations among the various regulator cells may help in understanding the events leading to the genesis of skin diseases. Ultimately, an ability to manipulate the function of regulator T cells according to the desired therapeutic effect will be the goal. Together, an integrated immunologic approach to therapy holds great promise in reducing the burden of psoriatic disease.

Now that cytokine and anti-cytokine therapies are increasingly used, it is a great opportunity to learn in detail the complex action of these molecules, including both their pro-inflammatory and immunosuppressive properties. The data present above clearly indicate that autoimmunity is a complex system. The immune response seems to be in a constant balancing act with itself. Emerging data indicate that a more realistic view is that these cytokines are not especially loyal to their functions. They switch sides, meaning that they do not have simple pro- or antiinflammatory actions.

Therefore, the mechanisms of action of the biologic therapies are more intricate than a simple blocking effect. The same cytokine can promote immune and inflammatory responses in some circumstances and inhibit responses in other settings. There is good and bad in every cytokine. Finally, the gut, skin or oral microbial communities simply primes the immune system. Therefore, psoriasis is a game played by many pieces and movements on a complex chessboard. The combinations of movements (cytokines) exert variable effects at different times during the evolution of autoimmune disease. There is much left to be done to dissect the complex and highly interactive effects of the players that one would have thought we understood very well, the Immunology game's inner logic. The application of game theory to Immunology thinking is our new proposition to explain autoimmune diseases and other immunologic responses. The objective is taking game theory seriously as a potential source of insight into the complex relationships that determine immune system function. 


\section{Author details}

Robyn S Fallen ${ }^{1}$, Anupam Mitra ${ }^{2}$, Laura Morrisey ${ }^{1}$ and Hermenio Lima ${ }^{3 *}$

*Address all correspondence to: hlima@mcmaster.ca

1 Michael G. DeGroote School of Medicine - Waterloo Regional Campus - McMaster University, Canada

2 UC Davis School of Medicine, Allergy and Clinical Immunology, Mather, CA, USA

3 Division of Dermatology, Department of Medicine, Michael G. DeGroote School of Medicine, McMaster University, Canada

\section{References}

[1] Vaz, N. M, Ramos, G. C, Pordeus, V, \& Carvalho, C. R. The conservative physiology of the immune system. A non-metaphoric approach to immunological activity. Clin Dev Immunol. (2006). Jun-Dec;13(2-4):133-42.

[2] Scarpa, R, Altomare, G, Marchesoni, A, \& Balato, N. Matucci Cerinic M, Lotti T, et al. Psoriatic disease: concepts and implications. J Eur Acad Dermatol Venereol. (2010). Jun; 24(6), 627-30.

[3] Lima, X. T, Seidler, E. M, Lima, H. C, \& Kimball, A. B. Long-term safety of biologics in dermatology. Dermatol Ther. (2009). Jan-Feb;, 22(1), 2-21.

[4] Feldmann, M, Brennan, F. M, \& Maini, R. Cytokines in autoimmune disorders. Int Rev Immunol. (1998).

[5] Squire, B. The Etiology of Psoriasis. Br Med J. (1873). Feb):141.

[6] Heaney, J. H. The Etiology and Treatment of Psoriasis. Br Med J. (1927). Dec):, 1136-7.

[7] Ingram, J. T. The approach to psoriasis. Br Med J. (1953). Sep 12;, 2(4836), 591-4.

[8] Harber, L. C, March, C, \& Ovary, Z. Lack of passive cutaneous anaphylaxis in psoriasis. Arch Dermatol. (1962). Jun; 85, 716-9.

[9] Aswaq, M, Farber, E. M, Moreci, A. P, \& Raffel, S. Immunologic reactions in psoriasis. Arch Dermatol. (1960). Nov;, 82, 663-6.

[10] Landau, J, Gross, B. G, Newcomer, V. D, \& Wright, E. T. Immunologic Response of Patients with Psoriasis. Arch Dermatol. (1965). Jun;, 91, 607-10.

[11] Harris, C. C. Malignancy during methotrexate and steroid therapy for psoriasis. Arch Dermatol. (1971). May; 103(5), 501-4. 
[12] Shuster, S. Research into psoriasis--the last decade. Br Med J. (1971). Jul 24; 3(5768), 236-9.

[13] Hunter, J. A, Ryan, T. J, \& Savin, J. A. Diseases of the skin. Present and future trends in approaches to skin disease. Br Med J. (1974). Feb 16;, 1(5902), 283-4.

[14] Braun-falco, O, \& Christophers, E. Structural aspects of initial psoriatic lesions. Arch Dermatol Forsch. (1974). , 251(2), 95-110.

[15] Krueger, G. G, Jederberg, W. W, Ogden, B. E, \& Reese, D. L. Inflammatory and immune cell function in psoriasis: II. Monocyte function, lymphokine production. J Invest Dermatol. (1978). Sep; 71(3), 195-201.

[16] Krueger, G. G, \& Jederberg, W. W. Alteration of HeLa cell growth equilibrium by supernatants of peripheral blood mononuclear cells from normal and psoriatic subjects. J Invest Dermatol. (1980). Mar; 74(3), 148-53.

[17] Champion, R. H. Psoriasis and its treatment. Br Med J (Clin Res Ed). (1981). Jan 31; 282(6261), 343-6.

[18] Bos, J. D, Hulsebosch, H. J, Krieg, S. R, Bakker, P. M, \& Cormane, R. H. Immunocompetent cells in psoriasis. In situ immunophenotyping by monoclonal antibodies. Arch Dermatol Res. (1983). , 275(3), 181-9.

[19] Baker, B. S, Swain, A. F, Griffiths, C. E, Leonard, J. N, Fry, L, \& Valdimarsson, H. The effects of topical treatment with steroids or dithranol on epidermal T lymphocytes and dendritic cells in psoriasis. Scand J Immunol. (1985). Nov;, 22(5), 471-7.

[20] Bos, J. D, \& Krieg, S. R. Psoriasis infiltrating cell immunophenotype: changes induced by PUVA or corticosteroid treatment in T-cell subsets, Langerhans' cells and interdigitating cells. Acta Derm Venereol. (1985). , 65(5), 390-7.

[21] Lieden, G, \& Skogh, M. Plasma exchange and leukapheresis in psoriasis--no effect? Arch Dermatol Res. (1986). , 278(6), 437-40.

[22] Valdimarsson, H, Bake, B. S, Jónsdótdr, I, \& Fry, L. Psoriasis: a disease of abnormal Keratinocyte proliferation induced by T lymphocytes. Immunology Today. (1986). , 7(9), 256-9.

[23] Schlaak, J. F, Buslau, M, Jochum, W, Hermann, E, Girndt, M, Gallati, H, et al. T cells involved in psoriasis vulgaris belong to the Th1 subset. J Invest Dermatol. (1994). Feb; 102(2), 145-9.

[24] Mosmann, T. R, Cherwinski, H, Bond, M. W, Giedlin, M. A, \& Coffman, R. L. Two types of murine helper $\mathrm{T}$ cell clone. I. Definition according to profiles of lymphokine activities and secreted proteins. J Immunol. (1986). Apr 1;, 136(7), 2348-57.

[25] Austin, L. M, Ozawa, M, Kikuchi, T, Walters, I. B, \& Krueger, J. G. The majority of epidermal T cells in Psoriasis vulgaris lesions can produce type 1 cytokines, interferon-gamma, interleukin-2, and tumor necrosis factor-alpha, defining TC1 (cytotoxic T 
lymphocyte) and TH1 effector populations: a type 1 differentiation bias is also measured in circulating blood T cells in psoriatic patients. J Invest Dermatol. (1999). Nov; 113(5), 752-9.

[26] Kagami, S, Rizzo, H. L, Kurtz, S. E, Miller, L. S, Blauvelt, A, But, I. L-23 a. n. d I. L-17A, \& Not, I. L. and IL-22, are required for optimal skin host defense against Candida albicans. J Immunol. (2010). Nov 1; 185(9), 5453-62.

[27] Abdi, K. IL-12: the role of versus p75. Scand J Immunol. (2002). Jul;56(1):1-11., 40.

[28] Vanaudenaerde, B. M, Verleden, S. E, Vos, R, De Vleeschauwer, S. I, Willems-widyastuti, A, Geenens, R, et al. Innate and Adaptive IL-17 Producing Lymphocytes in Chronic Inflammatory Lung Disorders. Am J Respir Crit Care Med. (2010). Nov 19.

[29] Nickoloff, B. J, \& Nestle, F. O. Recent insights into the immunopathogenesis of psoriasis provide new therapeutic opportunities. J Clin Invest. (2004). Jun;, 113(12), 1664-75.

[30] Kraan, M. C, Van Kuijk, A. W, Dinant, H. J, Goedkoop, A. Y, Smeets, T. J, De Rie, M. A, et al. Alefacept treatment in psoriatic arthritis: reduction of the effector T cell population in peripheral blood and synovial tissue is associated with improvement of clinical signs of arthritis. Arthritis Rheum. (2002). Oct; 46(10), 2776-84.

[31] Kalliolias, G. D, Gordon, R. A, \& Ivashkiv, L. B. Suppression of TNF-alpha and IL-1 signaling identifies a mechanism of homeostatic regulation of macrophages by IL-27. J Immunol. (2010). Dec 1; 185(11), 7047-56.

[32] Philipp, S, Wolk, K, Kreutzer, S, Wallace, E, Ludwig, N, Roewert, J, et al. The evaluation of psoriasis therapy with biologics leads to a revision of the current view of the pathogenesis of this disorder. Expert Opin Ther Targets. (2006). Dec;, 10(6), 817-31.

[33] Sobell, J. M, Kalb, R. E, \& Weinberg, J. M. Management of moderate to severe plaque psoriasis (part 2): clinical update on T-cell modulators and investigational agents. J Drugs Dermatol. (2009). Mar;, 8(3), 230-8.

[34] Monteleone, G, \& Pallone, F. MacDonald TT, Chimenti S, Costanzo A. Psoriasis: from pathogenesis to novel therapeutic approaches. Clin Sci (Lond). (2011). Jan;, 120(1), $1-11$.

[35] Albanesi, C, \& Pastore, S. Pathobiology of chronic inflammatory skin diseases: interplay between keratinocytes and immune cells as a target for anti-inflammatory drugs. Curr Drug Metab. (2010). Mar;, 11(3), 210-27.

[36] Endo, Y, Tamura, A, Ishikawa, O, Miyachi, Y, \& Hashimoto, T. Psoriasis vulgaris coexistent with epidermolysis bullosa acquisita. Br J Dermatol. (1997). Nov;, 137(5), 783-6. 
[37] Albanesi, C, De Pita, O, \& Girolomoni, G. Resident skin cells in psoriasis: a special look at the pathogenetic functions of keratinocytes. Clin Dermatol. (2007). Nov-Dec; 25(6), 581-8.

[38] Chen, S. C, De Groot, M, Kinsley, D, Laverty, M, Mcclanahan, T, Arreaza, M, et al. Expression of chemokine receptor CXCR3 by lymphocytes and plasmacytoid dendritic cells in human psoriatic lesions. Arch Dermatol Res. (2010). Mar;, 302(2), 113-23.

[39] Lima Ede ALima Mde A. Reviewing concepts in the immunopathogenesis of psoriasis. An Bras Dermatol. (2011). Nov-Dec;, 86(6), 1151-8.

[40] Krishnamurthy, K, Walker, A, Gropper, C. A, \& Hoffman, C. To treat or not to treat? Management of guttate psoriasis and pityriasis rosea in patients with evidence of group A Streptococcal infection. J Drugs Dermatol. (2010). Mar;, 9(3), 241-50.

[41] Bangert, C, Brunner, P. M, \& Stingl, G. Immune functions of the skin. Clin Dermatol. (2011). Jul-Aug;, 29(4), 360-76.

[42] Sercarz, E, \& Maverakis, E. van den Elzen P, Madakamutil L, Kumar V. Seven surprises in the TCR-centred regulation of immune responsiveness in an autoimmune system. Novartis Found Symp. (2003). discussion 71-6, 203-10., 252, 165-71.

[43] Iversen, O. J, Lysvand, H, \& Hagen, L. The autoantigen Pso a post-translational modification of SCCA molecules. Autoimmunity. (2011). May;44(3):229-34., 27.

[44] Kaufmann, S. H. Elie Metchnikoff's and Paul Ehrlich's impact on infection biology. Microbes Infect. (2008). Nov-Dec;10(14-15):1417-9.

[45] Von Neumann, J, \& Morgenstern, O. Theory of games and economic behavior. Princeton: Princeton university press; (1944).

[46] Gewin, V. The skin's secret surveillance system. Nature Publishing Group; (2012). updated Jul 26, 2012; cited 2012 September 2, 2012]; Available from: http:// www.nature.com/news/the-skin-s-secret-surveillance-system-1.11075.

[47] Naik, S, Bouladoux, N, Wilhelm, C, Molloy, M. J, Salcedo, R, Kastenmuller, W, et al. Compartmentalized control of skin immunity by resident commensals. Science. (2012). Aug 31; 337(6098), 1115-9.

[48] Morizane, S, \& Gallo, R. L. Antimicrobial peptides in the pathogenesis of psoriasis. J Dermatol. (2012). Mar;, 39(3), 225-30.

[49] Fung, I, Garrett, J. P, Shahane, A, \& Kwan, M. Do Bugs Control Our Fate? The Influence of the Microbiome on Autoimmunity. Curr Allergy Asthma Rep. (2012). Aug 11.

[50] Smith, J. M. The theory of games and the evolution of animal conflicts. J Theor Biol. (1974). Sep; 47(1), 209-21. 
[51] Steinbeck, J, \& Astro, R. The Log from the Sea of Cortez: Penguin Books Limited; (2001).

[52] Rook, G. A. Hygiene hypothesis and autoimmune diseases. Clin Rev Allergy Immunol. (2012). Feb;, 42(1), 5-15.

[53] Albanesi, C, Scarponi, C, Giustizieri, M. L, \& Girolomoni, G. Keratinocytes in inflammatory skin diseases. Curr Drug Targets Inflamm Allergy. (2005). Jun;, 4(3), 329-34.

[54] Lowes, M. A, Bowcock, A. M, \& Krueger, J. G. Pathogenesis and therapy of psoriasis. Nature. (2007). Feb 22;, 445(7130), 866-73.

[55] Schon, M. P, \& Boehncke, W. H. Psoriasis. N Engl J Med. (2005). May 5; 352(18), 1899-912.

[56] Nickoloff, B. J, \& Schroder, J. M. von den Driesch P, Raychaudhuri SP, Farber EM, Boehncke WH, et al. Is psoriasis a T-cell disease? Exp Dermatol. (2000). Oct; 9(5), 359-75.

[57] Okamura, H, Tsutsi, H, Komatsu, T, Yutsudo, M, Hakura, A, Tanimoto, T, et al. Cloning of a new cytokine that induces IFN-gamma production by T cells. Nature. (1995). Nov 2; 378(6552), 88-91.

[58] Biedermann, T, Rocken, M, \& Carballido, J. M. TH1 and TH2 lymphocyte development and regulation of $\mathrm{TH}$ cell-mediated immune responses of the skin. J Investig Dermatol Symp Proc. (2004). Jan;, 9(1), 5-14.

[59] Macatonia, S. E, Hosken, N. A, Litton, M, Vieira, P, Hsieh, C. S, Culpepper, J. A, et al. Dendritic cells produce IL-12 and direct the development of Th1 cells from naive CD4+ T cells. J Immunol. (1995). May 15; 154(10), 5071-9.

[60] Trinchieri, G. Interleukin-12: a cytokine at the interface of inflammation and immunity. Adv Immunol. (1998). , 70, 83-243.

[61] Hong, K, Berg, E. L, \& Ehrhardt, R. O. Persistence of pathogenic CD4+ Th1-like cells in vivo in the absence of IL-12 but in the presence of autoantigen. J Immunol. (2001). Apr $1 ;, 166(7), 4765-72$.

[62] Hong, K, Chu, A, Ludviksson, B. R, Berg, E. L, \& Ehrhardt, R. O. IL-12, independently of IFN-gamma, plays a crucial role in the pathogenesis of a murine psoriasis-like skin disorder. J Immunol. (1999). Jun 15;, 162(12), 7480-91.

[63] Monteleone, I, Pallone, F, \& Monteleone, G. Interleukin-23 and Th17 cells in the control of gut inflammation. Mediators Inflamm. (2009).

[64] Oppmann, B, Lesley, R, Blom, B, Timans, J. C, Xu, Y, Hunte, B, et al. Novel protein engages IL-12p40 to form a cytokine, IL-23, with biological activities similar as well as distinct from IL-12. Immunity. (2000). Nov;13(5):715-25., 19. 
[65] Lee, E, Trepicchio, W. L, Oestreicher, J. L, Pittman, D, Wang, F, Chamian, F, et al. Increased expression of interleukin 23 and p40 in lesional skin of patients with psoriasis vulgaris. J Exp Med. (2004). Jan 5;199(1):125-30., 19.

[66] Toichi, E, Torres, G, Mccormick, T. S, Chang, T, Mascelli, M. A, Kauffman, C. L, et al. An anti-IL-12antibody down-regulates type 1 cytokines, chemokines, and IL-12/IL-23 in psoriasis. J Immunol. (2006). Oct 1;177(7):4917-26., 40.

[67] Piskin, G, Sylva-steenland, R. M, Bos, J. D, \& Teunissen, M. B. In vitro and in situ expression of IL-23 by keratinocytes in healthy skin and psoriasis lesions: enhanced expression in psoriatic skin. J Immunol. (2006). Feb 1; 176(3), 1908-15.

[68] Wilson, N. J, Boniface, K, Chan, J. R, Mckenzie, B. S, Blumenschein, W. M, Mattson, J. D, et al. Development, cytokine profile and function of human interleukin 17-producing helper T cells. Nat Immunol. (2007). Sep;, 8(9), 950-7.

[69] Lillis, J. V, Guo, C. S, Lee, J. J, Blauvelt, A, \& Increased, I. L. expression in palmoplantar psoriasis and hyperkeratotic hand dermatitis. Arch Dermatol. (2010). Aug; 146(8), 918-9.

[70] Capon, F. Di Meglio P, Szaub J, Prescott NJ, Dunster C, Baumber L, et al. Sequence variants in the genes for the interleukin-23 receptor (IL23R) and its ligand (IL12B) confer protection against psoriasis. Hum Genet. (2007). Sep; 122(2), 201-6.

[71] Cargill, M, Schrodi, S. J, Chang, M, Garcia, V. E, Brandon, R, Callis, K. P, et al. A large-scale genetic association study confirms IL12B and leads to the identification of IL23R as psoriasis-risk genes. Am J Hum Genet. (2007). Feb;, 80(2), 273-90.

[72] Nair, R. P, Ding, J, Duffin, K. C, Helms, C, Voorhees, J. J, Krueger, G. G, et al. Psoriasis bench to bedside: genetics meets immunology. Arch Dermatol. (2009). Apr; 145(4), 462-4.

[73] Tonel, G, Conrad, C, \& Laggner, U. Di Meglio P, Grys K, McClanahan TK, et al. Cutting edge: A critical functional role for IL-23 in psoriasis. J Immunol. (2010). Nov 15; 185(10), 5688-91.

[74] Aggarwal, S, Ghilardi, N, Xie, M. H, De Sauvage, F. J, \& Gurney, A. L. Interleukin-23 promotes a distinct CD4 $\mathrm{T}$ cell activation state characterized by the production of interleukin-17. J Biol Chem. (2003). Jan 17;, 278(3), 1910-4.

[75] Miossec, P, Korn, T, \& Kuchroo, V. K. Interleukin-17 and type 17 helper T cells. N Engl J Med. (2009). Aug 27; 361(9), 888-98.

[76] Romagnani, S, Maggi, E, Liotta, F, Cosmi, L, \& Annunziato, F. Properties and origin of human Th17 cells. Mol Immunol. (2009). Nov;, 47(1), 3-7.

[77] Korn, T, Bettelli, E, Oukka, M, Kuchroo, V. K, \& Th, I. L. Cells. Annu Rev Immunol. (2009). , 27, 485-517. 
[78] Zheng, Y, Danilenko, D. M, Valdez, P, Kasman, I, Eastham-anderson, J, Wu, J, et al. Interleukin-22, a $\mathrm{T}(\mathrm{H}) 17$ cytokine, mediates IL-23-induced dermal inflammation and acanthosis. Nature. (2007). Feb 8;, 445(7128), 648-51.

[79] Ghoreschi, K, Laurence, A, Yang, X. P, Tato, C. M, Mcgeachy, M. J, Konkel, J. E, et al. Generation of pathogenic $\mathrm{T}(\mathrm{H}) 17$ cells in the absence of TGF-beta signalling. Nature. (2010). Oct 21; 467(7318), 967-71.

[80] Volpe, E, Servant, N, Zollinger, R, Bogiatzi, S. I, Hupe, P, Barillot, E, et al. A critical function for transforming growth factor-beta, interleukin 23 and proinflammatory cytokines in driving and modulating human $\mathrm{T}(\mathrm{H})-17$ responses. Nat Immunol. (2008). Jun; 9(6), 650-7.

[81] Infante-duarte, C, Horton, H. F, Byrne, M. C, \& Kamradt, T. Microbial lipopeptides induce the production of IL-17 in Th cells. J Immunol. (2000). Dec $1 ;$; 165(11), 6107-15.

[82] Harrington, L. E, Hatton, R. D, Mangan, P. R, Turner, H, Murphy, T. L, Murphy, K. $\mathrm{M}$, et al. Interleukin 17-producing CD4+ effector T cells develop via a lineage distinct from the T helper type 1 and 2 lineages. Nat Immunol. (2005). Nov;, 6(11), 1123-32.

[83] Zaba, L. C, Cardinale, I, Gilleaudeau, P, Sullivan-whalen, M, Suarez-farinas, M, Fuentes-duculan, J, et al. Amelioration of epidermal hyperplasia by TNF inhibition is associated with reduced Th17 responses. J Exp Med. (2007). Dec 24;, 204(13), 3183-94.

[84] Harper, E. G, Guo, C, Rizzo, H, Lillis, J. V, Kurtz, S. E, Skorcheva, I, et al. Th17 cytokines stimulate CCL20 expression in keratinocytes in vitro and in vivo: implications for psoriasis pathogenesis. J Invest Dermatol. (2009). Sep; 129(9), 2175-83.

[85] Johansen, C, Usher, P. A, Kjellerup, R. B, Lundsgaard, D, Iversen, L, \& Kragballe, K. Characterization of the interleukin-17 isoforms and receptors in lesional psoriatic skin. Br J Dermatol. (2009). Feb; 160(2), 319-24.

[86] Lowes, M. A, Kikuchi, T, Fuentes-duculan, J, Cardinale, I, Zaba, L. C, Haider, A. S, et al. Psoriasis vulgaris lesions contain discrete populations of Th1 and Th17 T cells. J Invest Dermatol. (2008). May;, 128(5), 1207-11.

[87] Boniface, K, Guignouard, E, Pedretti, N, Garcia, M, Delwail, A, Bernard, F. X, et al. A role for $\mathrm{T}$ cell-derived interleukin 22 in psoriatic skin inflammation. Clin Exp Immunol. (2007). Dec; 1 150(3), 407-15.

[88] Nograles, K. E, Zaba, L. C, Guttman-yassky, E, Fuentes-duculan, J, Suarez-farinas, M, Cardinale, I, et al. Th17 cytokines interleukin (IL)-17 and IL-22 modulate distinct inflammatory and keratinocyte-response pathways. Br J Dermatol. (2008). Nov; 159(5), 1092-102.

[89] Albanesi, C, Scarponi, C, Cavani, A, Federici, M, Nasorri, F, \& Girolomoni, G. Interleukin-17 is produced by both Th1 and Th2 lymphocytes, and modulates interferongamma- and interleukin-4-induced activation of human keratinocytes. J Invest Dermatol. (2000). Jul; , 115(1), 81-7. 
[90] Wolk, K, Witte, E, Wallace, E, Docke, W. D, Kunz, S, Asadullah, K, et al. IL-22 regulates the expression of genes responsible for antimicrobial defense, cellular differentiation, and mobility in keratinocytes: a potential role in psoriasis. Eur J Immunol. (2006). May;, 36(5), 1309-23.

[91] Liang, S. C, Tan, X. Y, Luxenberg, D. P, Karim, R, Dunussi-joannopoulos, K, Collins, $\mathrm{M}$, et al. Interleukin (IL)-22 and IL-17 are coexpressed by Th17 cells and cooperatively enhance expression of antimicrobial peptides. J Exp Med. (2006). Oct 2;, 203(10), 2271-9.

[92] Sa, S. M, Valdez, P. A, Wu, J, Jung, K, Zhong, F, Hall, L, et al. The effects of IL-20 subfamily cytokines on reconstituted human epidermis suggest potential roles in $\mathrm{cu}^{-}$ taneous innate defense and pathogenic adaptive immunity in psoriasis. J Immunol. (2007). Feb 15; 178(4), 2229-40.

[93] Chan, J. R, Blumenschein, W, Murphy, E, Diveu, C, Wiekowski, M, Abbondanzo, S, et al. IL-23 stimulates epidermal hyperplasia via TNF and IL-20R2-dependent mechanisms with implications for psoriasis pathogenesis. J Exp Med. (2006). Nov 27; 203(12), 2577-87.

[94] Kopp, T, Lenz, P, Bello-fernandez, C, Kastelein, R. A, Kupper, T. S, \& Stingl, G. IL-23 production by cosecretion of endogenous and transgenic p40 in keratin 14/p40 transgenic mice: evidence for enhanced cutaneous immunity. J Immunol. (2003). Jun 1;170(11):5438-44., 19.

[95] Rizzo, H. L, Kagami, S, Phillips, K. G, Kurtz, S. E, Jacques, S. L, Blauvelt, A, \& Psoriasis-like, I. L-23-m. e. d. i. a. t. e. d. epidermal hyperplasia is dependent on IL-17A. J Immunol. (2011). Feb 1; 186(3), 1495-502.

[96] Nestle, F. O, Kaplan, D. H, \& Barker, J. Psoriasis. N Engl J Med. (2009). Jul 30;, 361(5), 496-509.

[97] Watanabe, H, Kawaguchi, M, Fujishima, S, Ogura, M, Matsukura, S, Takeuchi, H, et al. Functional characterization of IL-17F as a selective neutrophil attractant in psoriasis. J Invest Dermatol. (2009). Mar;, 129(3), 650-6.

[98] Yeilding, N, Szapary, P, Brodmerkel, C, Benson, J, Plotnick, M, Zhou, H, et al. Development of the IL-12/23 antagonist ustekinumab in psoriasis: past, present, and future perspectives. Ann N Y Acad Sci. (2011). Mar;, 1222, 30-9.

[99] Lima, X. T, Abuabara, K, Kimball, A. B, \& Lima, H. C. Briakinumab. Expert Opin Biol Ther. (2009). Aug;, 9(8), 1107-13.

[100] Leonardi, C. L, Kimball, A. B, Papp, K. A, Yeilding, N, Guzzo, C, Wang, Y, et al. Efficacy and safety of ustekinumab, a human interleukin-12/23 monoclonal antibody, in patients with psoriasis: 76-week results from a randomised, double-blind, placebocontrolled trial (PHOENIX 1). Lancet. (2008). May 17;, 371(9625), 1665-74. 
[101] Parham, C, Chirica, M, Timans, J, Vaisberg, E, Travis, M, Cheung, J, et al. A receptor for the heterodimeric cytokine IL-23 is composed of IL-12Rbeta1 and a novel cytokine receptor subunit, IL-23R. J Immunol. (2002). Jun 1;, 168(11), 5699-708.

[102] Trinchieri, G, Pflanz, S, Kastelein, R. A, \& The, I. L. family of heterodimeric cytokines: new players in the regulation of T cell responses. Immunity. (2003). Nov; 19(5), 641-4.

[103] Becher, B, Durell, B. G, \& Noelle, R. J. Experimental autoimmune encephalitis and inflammation in the absence of interleukin-12. J Clin Invest. (2002). Aug;, 110(4), 493-7.

[104] Liu, J, Marino, M. W, Wong, G, Grail, D, Dunn, A, Bettadapura, J, et al. TNF is a potent anti-inflammatory cytokine in autoimmune-mediated demyelination. Nat Med. (1998). Jan;, 4(1), 78-83.

[105] Ramos-casals, M, Brito-zeron, P, Soto, M. J, Cuadrado, M. J, \& Khamashta, M. A. Autoimmune diseases induced by TNF-targeted therapies. Best Pract Res Clin Rheumatol. (2008). Oct; $22(5), 847-61$.

[106] Dinarello, C. A. Anti-cytokine therapeutics and infections. Vaccine. (2003). Jun 1;21 Suppl 2:S, 24-34.

[107] MacLennan CFieschi C, Lammas DA, Picard C, Dorman SE, Sanal O, et al. Interleukin (IL)-12 and IL-23 are key cytokines for immunity against Salmonella in humans. J Infect Dis. (2004). Nov 15; 190(10), 1755-7.

[108] Rudner, X. L, Happel, K. I, Young, E. A, Shellito, J. E, \& Interleukin-23, I. L. IL-17 cytokine axis in murine Pneumocystis carinii infection. Infect Immun. (2007). Jun; 75(6), 3055-61.

[109] Shear, N. H, Prinz, J, Papp, K, Langley, R. G, \& Gulliver, W. P. Targeting the interleukin-12/23 cytokine family in the treatment of psoriatic disease. J Cutan Med Surg. (2008). Dec;12 Suppl 1:S, 1-10.

[110] Chackerian, A. A, Chen, S. J, Brodie, S. J, Mattson, J. D, Mcclanahan, T. K, Kastelein, R. A, et al. Neutralization or absence of the interleukin-23 pathway does not compromise immunity to mycobacterial infection. Infect Immun. (2006). Nov;, 74(11), 6092-9.

[111] Dumoutier, L, Louahed, J, \& Renauld, J. C. Cloning and characterization of IL-10-related T cell-derived inducible factor (IL-TIF), a novel cytokine structurally related to IL-10 and inducible by IL-9. J Immunol. (2000). Feb 15; 164(4), 1814-9.

[112] Wolk, K, Kunz, S, Asadullah, K, \& Sabat, R. Cutting edge: immune cells as sources and targets of the IL-10 family members? J Immunol. (2002). Jun 1; 168(11), 5397-402.

[113] Nograles, K. E, Zaba, L. C, Shemer, A, Fuentes-duculan, J, Cardinale, I, Kikuchi, T, et al. IL-22-producing "T22" T cells account for upregulated IL-22 in atopic dermatitis despite reduced IL-17-producing TH17 T cells. J Allergy Clin Immunol. (2009). Jun;e2., 123(6), 1244-52. 
[114] Duhen, T, Geiger, R, Jarrossay, D, Lanzavecchia, A, \& Sallusto, F. Production of interleukin 22 but not interleukin 17 by a subset of human skin-homing memory $\mathrm{T}$ cells. Nat Immunol. (2009). Aug;, 10(8), 857-63.

[115] Wolk, K, Haugen, H. S, Xu, W, Witte, E, Waggie, K, Anderson, M, et al. IL-22 and IL-20 are key mediators of the epidermal alterations in psoriasis while IL-17 and IFNgamma are not. J Mol Med. (2009). May;, 87(5), 523-36.

[116] Wolk, K, Witte, E, Warszawska, K, Schulze-tanzil, G, Witte, K, Philipp, S, et al. The Th17 cytokine IL-22 induces IL-20 production in keratinocytes: A novel immunological cascade with potential relevance in psoriasis. Eur J Immunol. (2009). Oct 14.

[117] Sabat, R, \& Wolk, K. Research in practice: IL-22 and IL-20: significance for epithelial homeostasis and psoriasis pathogenesis. J Dtsch Dermatol Ges. (2011). Jan 21.

[118] Boniface, K, Bernard, F. X, Garcia, M, Gurney, A. L, Lecron, J. C, \& Morel, F. IL-22 inhibits epidermal differentiation and induces proinflammatory gene expression and migration of human keratinocytes. J Immunol. (2005). Mar 15; 174(6), 3695-702.

[119] Wolk, K, Kunz, S, Witte, E, Friedrich, M, Asadullah, K, \& Sabat, R. IL-22 increases the innate immunity of tissues. Immunity. (2004). Aug;, 21(2), 241-54.

[120] Kotenko, S. V, Izotova, L. S, Mirochnitchenko, O. V, Esterova, E, Dickensheets, H, Donnelly, R. P, et al. Identification of the functional interleukin-22 (IL-22) receptor complex: the IL-10R2 chain (IL-10Rbeta ) is a common chain of both the IL-10 and IL-22 (IL-10-related T cell-derived inducible factor, IL-TIF) receptor complexes. J Biol Chem. (2001). Jan 26; 276(4), 2725-32.

[121] Savan, R, Mcfarland, A. P, Reynolds, D. A, Feigenbaum, L, Ramakrishnan, K, Karwan, M, et al. A novel role for IL-22R1 as a driver of inflammation. Blood. (2011). Jan $13 ;, 117(2), 575-84$.

[122] Jones, B. C, Logsdon, N. J, \& Walter, M. R. Structure of IL-22 bound to its high-affinity IL-22R1 chain. Structure. (2008). Sep 10;, 16(9), 1333-44.

[123] Lejeune, D, Dumoutier, L, Constantinescu, S, Kruijer, W, Schuringa, J. J, Renauld, J. C, \& Interleukin-22, I. L. activates the JAK/STAT, ERK, JNK, and MAP kinase pathways in a rat hepatoma cell line. Pathways that are shared with and distinct from IL-10. J Biol Chem. (2002). Sep 13;277(37):33676-82., 38.

[124] Horwitz, D. A, Gray, J. D, \& Zheng, S. G. The potential of human regulatory T cells generated ex vivo as a treatment for lupus and other chronic inflammatory diseases. Arthritis Res. (2002). , 4(4), 241-6.

[125] Korn, T, Mitsdoerffer, M, \& Kuchroo, V. K. Immunological basis for the development of tissue inflammation and organ-specific autoimmunity in animal models of multiple sclerosis. Results Probl Cell Differ. (2010). , 51, 43-74. 
[126] Ramsdell, F, \& Fowlkes, B. J. Clonal deletion versus clonal anergy: the role of the thymus in inducing self tolerance. Science. (1990). Jun 15;, 248(4961), 1342-8.

[127] Sakaguchi, S, Toda, M, Asano, M, Itoh, M, Morse, S. S, \& Sakaguchi, N. T cell-mediated maintenance of natural self-tolerance: its breakdown as a possible cause of various autoimmune diseases. J Autoimmun. (1996). Apr;" 9(2), 211-20.

[128] Sakaguchi, S, Sakaguchi, N, Shimizu, J, Yamazaki, S, Sakihama, T, Itoh, M, et al. Immunologic tolerance maintained by CD25+ CD4+ regulatory $\mathrm{T}$ cells: their common role in controlling autoimmunity, tumor immunity, and transplantation tolerance. Immunol Rev. (2001). Aug;, 182, 18-32.

[129] Gershon, R. K, \& Kondo, K. Infectious immunological tolerance. Immunology. (1971). $\mathrm{Dec}_{\text {; }}$ 21(6), 903-14.

[130] Dorf, M. E, \& Benacerraf, B. Suppressor cells and immunoregulation. Annu Rev Immunol. (1984). , 2, 127-57.

[131] Green, D. R, \& Webb, D. R. Saying the'S' word in public. Immunol Today. (1993). Nov; $14(11), 523-5$.

[132] Shevach, E. M, Thornton, A, \& Suri-payer, E. T lymphocyte-mediated control of autoimmunity. Novartis Found Symp. (1998). discussion 11-30., 215, 200-11.

[133] Belkaid, Y, Blank, R. B, \& Suffia, I. Natural regulatory T cells and parasites: a common quest for host homeostasis. Immunol Rev. (2006). Aug; 212, 287-300.

[134] Weiner, H. L. da Cunha AP, Quintana F, Wu H. Oral tolerance. Immunol Rev. (2011). May;, 241(1), 241-59.

[135] Shehata, I. H, \& Elghandour, T. M. A possible pathogenic role of CD4+CD25+ T-regulatory cells in psoriasis. Egypt J Immunol. (2007). , 14(1), 21-31.

[136] Sabat, R, Philipp, S, Hoflich, C, Kreutzer, S, Wallace, E, Asadullah, K, et al. Immunopathogenesis of psoriasis. Exp Dermatol. (2007). Oct; 16(10), 779-98.

[137] Sugiyama, H, Gyulai, R, Toichi, E, Garaczi, E, Shimada, S, Stevens, S. R, et al. Dysfunctional blood and target tissue CD4+CD25high regulatory $\mathrm{T}$ cells in psoriasis: mechanism underlying unrestrained pathogenic effector T cell proliferation. J Immunol. (2005). Jan $1 ;$; 174(1), 164-73.

[138] Wilhelm, A. J, Zabalawi, M, Owen, J. S, Shah, D, Grayson, J. M, Major, A. S, et al. Apolipoprotein A-I modulates regulatory T cells in autoimmune LDLr-/-, ApoA-I-/mice. J Biol Chem. (2010). Nov 12;, 285(46), 36158-69.

[139] Ortega, C, Fernandez, A. S, Carrillo, J. M, Romero, P, Molina, I. J, Moreno, J. C, et al. IL-17-producing CD8+ T lymphocytes from psoriasis skin plaques are cytotoxic effector cells that secrete Th17-related cytokines. J Leukoc Biol. (2009). Aug;, 86(2), 435-43. 
[140] Yu, P, Lee, Y, Liu, W, Krausz, T, Chong, A, Schreiber, H, et al. Intratumor depletion of CD4+ cells unmasks tumor immunogenicity leading to the rejection of late-stage tumors. J Exp Med. (2005). Mar 7; 201(5), 779-91.

[141] Abrams, J. R, Kelley, S. L, Hayes, E, Kikuchi, T, Brown, M. J, Kang, S, et al. Blockade of T lymphocyte costimulation with cytotoxic T lymphocyte-associated antigen 4-immunoglobulin (CTLA4Ig) reverses the cellular pathology of psoriatic plaques, including the activation of keratinocytes, dendritic cells, and endothelial cells. J Exp Med. (2000). Sep $4 ;$, 192(5), 681-94.

[142] Sewgobind, V. D, Van Der Laan, L. J, Kho, M. M, Kraaijeveld, R, Korevaar, S. S, Mol, $\mathrm{W}$, et al. The calcineurin inhibitor tacrolimus allows the induction of functional CD4CD25 regulatory T cells by rabbit anti-thymocyte globulins. Clin Exp Immunol. (2010). Aug; 161(2), 364-77.

[143] Vukmanovic-stejic, M, Mcquaid, A, Birch, K. E, Reed, J. R, Macgregor, C, Rustin, M. $\mathrm{H}$, et al. Relative impact of CD4+CD25+ regulatory $\mathrm{T}$ cells and tacrolimus on inhibition of T-cell proliferation in patients with atopic dermatitis. Br J Dermatol. (2005). Oct; $, 153(4), 750-7$.

[144] De Rezende, L. C, Silva, I. V, Rangel, L. B, \& Guimaraes, M. C. Regulatory T cell as a target for cancer therapy. Arch Immunol Ther Exp (Warsz). (2010). Jun;, 58(3), 179-90.

[145] Lutsiak, M. E, Semnani, R. T, De Pascalis, R, Kashmiri, S. V, Schlom, J, \& Sabzevari, $\mathrm{H}$. Inhibition of CD4(+)25+ T regulatory cell function implicated in enhanced immune response by low-dose cyclophosphamide. Blood. (2005). Apr 1;, 105(7), 2862-8.

[146] Cerullo, V, Diaconu, I, Kangasniemi, L, Rajecki, M, Escutenaire, S, Koski, A, et al. Immunological Effects of Low-dose Cyclophosphamide in Cancer Patients Treated With Oncolytic Adenovirus. Mol Ther. (2011). Jun 14.

[147] Ikezawa, Y, Nakazawa, M, Tamura, C, Takahashi, K, Minami, M, \& Ikezawa, Z. Cyclophosphamide decreases the number, percentage and the function of CD25+ CD4+ regulatory T cells, which suppress induction of contact hypersensitivity. J Dermatol Sci. (2005). Aug;, 39(2), 105-12.

[148] Stock, P, Akbari, O, Dekruyff, R. H, \& Umetsu, D. T. Respiratory tolerance is inhibited by the administration of corticosteroids. J Immunol. (2005). Dec 1; 175(11), 7380-7.

[149] Papp, K. A, Leonardi, C, Menter, A, Ortonne, J. P, Krueger, J. G, Kricorian, G, et al. Brodalumab, an anti-interleukin-17-receptor antibody for psoriasis. N Engl J Med. (2012). Mar 29;, 366(13), 1181-9.

[150] Leonardi, C, Matheson, R, Zachariae, C, Cameron, G, Li, L, Edson-heredia, E, et al. Anti-interleukin-17 monoclonal antibody ixekizumab in chronic plaque psoriasis. $\mathrm{N}$ Engl J Med. (2012). Mar 29;, 366(13), 1190-9.

[151] Sivamani, R. K, Goodarzi, H, Garcia, M. S, Raychaudhuri, S. P, Wehrli, L. N, Ono, Y, et al. Biologic Therapies in the Treatment of Psoriasis: A Comprehensive Evidence- 
Based Basic Science and Clinical Review and a Practical Guide to Tuberculosis Monitoring. Clin Rev Allergy Immunol. (2012). Feb 5.

[152] Kopf, M, Bachmann, M. F, \& Marsland, B. J. Averting inflammation by targeting the cytokine environment. Nat Rev Drug Discov. (2010). Sep; 9(9), 703-18. 
